\title{
Lockdown Britain: Evidence for reduced incidence and severity of some non-COVID acute medical illnesses
}

\author{
Authors: Miles C Allison, ${ }^{\mathrm{A}}$ Nicholas A Doyle, ${ }^{\mathrm{B}}$ Giles Greene, ${ }^{\mathrm{C}}$ Arif Mahmood, ${ }^{\mathrm{D}}$ Myer Glickman, ${ }^{\mathrm{E}}$ Aine $\mathrm{K}$ Jones ${ }^{\mathrm{F}}$ \\ and Paul E Mizen ${ }^{G}$
}

\begin{abstract}
Large reductions in emergency department attendances and hospitalisations with non-COVID acute medical illness early during the pandemic were attributed to reluctance to seek medical help and higher referral thresholds. Here, we compare acute medical admissions with a comparison cohort from 2017. Deaths in the same geographic area were examined, and Wales-wide deaths during these 4 weeks in 2020 were compared with a seasonally matched period in 2019. There were $\mathbf{5 2 8}$ patients admitted with non-COVID illness in $\mathbf{2 0 2 0}$, versus 924 in 2017 (a reduction of 43\%). Deaths from nonCOVID causes increased by $10.9 \%$ compared with 2017 , over half this rise being from neurological causes including stroke and dementia. While far fewer patients required hospitalisation as medical emergencies, rises in local nonCOVID deaths proved small. Wales-wide non-COVID deaths rose by just $1 \%$ compared with 2019 . The findings suggest that changes in population behaviour and lifestyle during lockdown brought about unforeseen health benefits.
\end{abstract}

KEYWORDS: population, population behaviour, atmospheric pollution, lockdown, COVID-19

DOI: $10.7861 /$ clinmed.2020-0586

\section{Introduction}

The COVID-19 pandemic has presented an unprecedented challenge to health services in most parts of the world. Notwithstanding the surge in hospitalisations with COVID-19, early indications were that admissions due to non-COVID acute medical illnesses, and attendances in emergency departments

Authors: ${ }^{\text {A }}$ consultant physician and gastroenterologist, Royal Gwent Hospital, Newport, UK; ${ }^{\text {B }}$ foundation year-1 doctor, Royal Gwent Hospital, Newport, UK; Chead of population cancer research at Public Health Wales, Knowledge Directorate, Cardiff, UK;

${ }^{\mathrm{D}}$ consultant in public health medicine, Aneurin Bevan University Health Board Headquarters, Newport, UK; Ehead of quality, methods and international, Office for National Statistics, Newport, UK; F foundation year-1 doctor, Princess of Wales Hospital, Bridgend, UK; ${ }^{G}$ consultant in acute medicine and gastroenterology, Royal Gwent Hospital, Newport, UK both reduced rapidly. ${ }^{1,2}$ It is assumed these reductions reflected reluctance to seek medical help, and primary care adopting higher referral thresholds than in normal times. Some suggested that many people with acute illness are dying in the community instead of accessing timely treatment. ${ }^{3,4}$

The Office for National Statistics (ONS) reports that 'we are [now] spending less time on travelling and work, and more on free time, gardening and DIY, and sleep and rest.' ${ }^{5}$ While not necessarily applicable to all ages or socioeconomic groups, the profound changes in population behaviour and lifestyle arising from the lockdown and social distancing are summarised in Table 1. A paradigm of potential triggers for some acute illnesses during normal times is shown in Figure 1. We considered that the large drop in presentations with exacerbations of chronic respiratory and cardiac diseases seemed out of proportion to changes in referral patterns and behaviour. We therefore reviewed our medical admission case mix in parallel with contemporaneous data on hospital and community deaths that occurred in a defined area and compared the findings with those from a historical cohort ascertained 3 years earlier.

\section{Methods}

\section{Study design and patients}

The Royal Gwent Hospital provides secondary care to a mixed urban and rural catchment population in southeast Wales totalling 360,000 people. Some services (such as acute stroke care) are provided for the former county of Gwent and parts of Powys. Analysis of medical emergencies and deaths during the two 4-week time frames was restricted to those from the following postcode areas: NP10, NP11, NP12, NP16, NP18, NP19, NP20 and NP26; in addition to CF81, CF82 and CF83. The study was approved as a service evaluation by the Research and Development Department of the Aneurin Bevan University Health Board, and the data collection process by the local Caldicott guardian.

\section{Data collection}

All acute medical admissions between 23 March 2020 and 19 April 2020 were identified using the health board's clinical workstation (CWS). Those admitted with medical illnesses under critical care consultants were also included. Patients not remaining in hospital overnight were only included if they died in a medical or critical 
Table 1. Changes in population behaviour and lifestyle during lockdown

$\begin{array}{lll}\text { More } & \text { Less } & \text { None } \\ \text { Working from home } & \text { Pollution } & \text { Conferences or meetings } \\ \text { Sleep } & \text { Bullying, work confrontations, me too } & \text { Shaking hands } \\ \text { Dressing down } & \text { hashtags and deadlines } & \text { Qualified hairdressing } \\ \text { Relaxed pace: people rarely in hurry } & \text { Dressing up and make-up } & \text { Club and group gatherings } \\ \text { Social media banter } & \text { Beer drinking } & \text { Crowds } \\ \text { Community spirit } & \text { Acute alcohol intoxication } & \text { Spectator sport } \\ \text { Parking places } & \text { Aircraft, road and train noise } & \text { Competitive sport } \\ \text { Appreciation of the NHS } & \text { Travel, traffic jams and road traffic accidents } & \text { House buying or selling, moving or evictions } \\ \text { Interaction with family members in } & \text { School runs } & \text { Extra-marital relationships and prostitution } \\ \text { household } & \text { Cold callers } & \\ & \text { Gambling and betting } & \end{array}$

care ward on their admission day. A corresponding historical cohort of patients admitted between 13 March 2017 and 9 April 2017 had previously been gathered during a student project by two of the authors.

ONS was asked for deaths and their causes by International Statistical Classification of Diseases and Related Health Problems, 10th revision (ICD-10) chapter among residents in the catchment area during the corresponding two 4 -week time periods. One author examined trends in COVID-19 and non-COVID deaths throughout Wales during 4-week timeframes in March to April, 2019 and 2020.

Given that the disease coding within the ICD-10 chapter classifies Alzheimer's disease and vascular dementia under 'Diseases of the nervous system' and stroke under 'Diseases of the circulatory system', we moved our stroke deaths into the former category to highlight any differences in cardiac deaths between the two cohorts.

For those aged less than 65 years, a detailed analysis of admissions, deaths and lengths of stay was done to examine whether there was any suggestion of different illness severity among those presenting with exacerbations of cardiac and respiratory disease.

Local data on air pollution was gathered using an air information resource provided by the UK Department for Environment, Food
\& Rural Affairs (https://uk-air.defra.gov.uk/data). Atmospheric concentrations of nitrogen dioxide $\left(\mathrm{NO}_{2}\right)$, ozone $\left(\mathrm{O}_{3}\right)$ and particulate matter $\left(\mathrm{PM}_{2.5}\right)$ are measured hourly. There are four automatic monitoring stations located within the study catchment area, of which the Newport and Cwmbran stations sample background air, and Chepstow and Hafod-yr-ynys sample roadside air.

\section{Statistical analysis}

Differences in numbers and demographics of admissions and deaths between the two 4-week blocks were examined by Pearson chi-squared testing. Using multivariable negative binomial regression, we assessed differences in length of stay across the different diagnosis codes between 2017 and 2020 controlling for age and sex. We implemented a two-way interaction between diagnosis code and year to compare length of stay in the two time periods. Differences in mean daily concentrations of local atmospheric pollutants between the two time periods were examined by t-testing.

\section{Results}

During the 2017 block, 1,078 patients were admitted but 154 were excluded as they resided outside the catchment area.
Fig 1. Network of triggers of acute medical illness in non-COVID-19 pandemic times. COPD = chronic obstructive pulmonary disease.

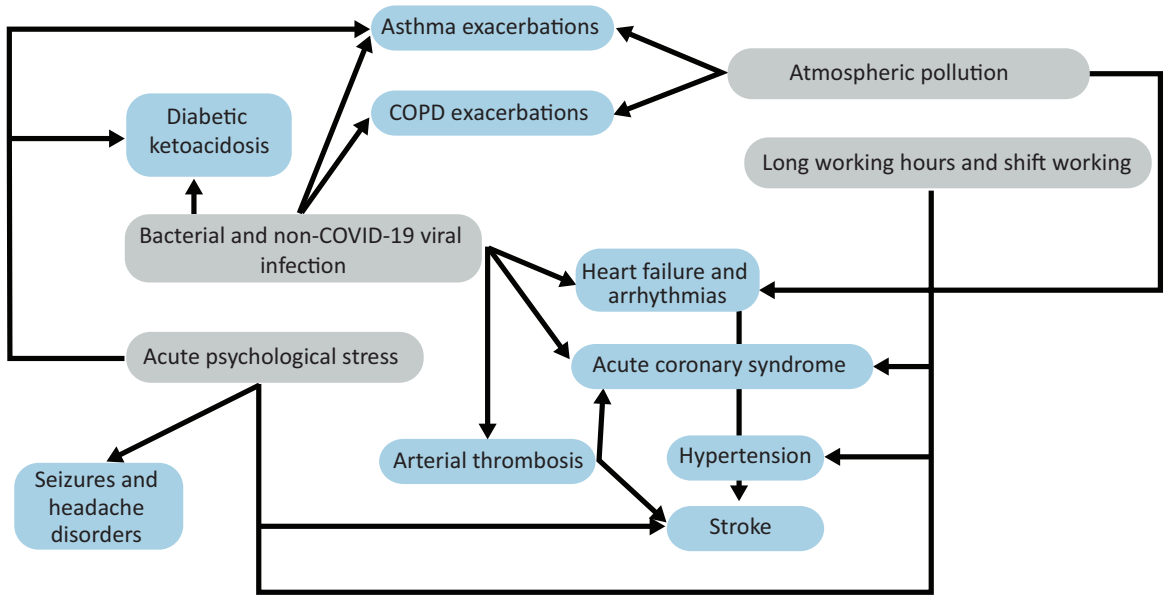


Table 2. Admissions to Royal Gwent Hospital with acute medical emergencies from the study catchment area during two 4-week blocks

\begin{tabular}{|c|c|c|c|c|}
\hline Disease category & 2017, n (\%) & 2020, n (\%) & Change, \% & $\mathrm{p}$ value \\
\hline COVID-19 & & 235 & & \\
\hline Cardiac & & & & 0.001 \\
\hline Arrhythmias & $51(34)$ & $19(40)$ & $-63 \%$ & \\
\hline Acute coronary syndrome & $46(31)$ & $22(47)$ & $-52 \%$ & \\
\hline Cardiac failure (non-valvular) & $40(27)$ & $0(0)$ & $-100 \%$ & \\
\hline Other & $12(8)$ & $6(13)$ & $-50 \%$ & \\
\hline Total cardiac & 149 & 47 & $-68 \%$ & \\
\hline Respiratory (excluding cancer and pneumonia) & & & & 0.013 \\
\hline Asthma exacerbations & $16(20)$ & $7(23)$ & $-64 \%$ & \\
\hline COPD exacerbations & $41(51)$ & $6(20)$ & $-85 \%$ & \\
\hline Pulmonary embolism & $14(17)$ & $7(23)$ & $-50 \%$ & \\
\hline Other & $10(12)$ & $10(33)$ & $0 \%$ & \\
\hline Total respiratory & 81 & 30 & $-63 \%$ & \\
\hline Pneumonia (negative SARS-CoV-2 swab in 2020) & 110 & 107 & $-3 \%$ & \\
\hline Other infections & 145 & 49 & $-66 \%$ & 0.001 \\
\hline Metabolic & 57 & 20 & $-65 \%$ & 0.317 \\
\hline Neurological & & & & 0.02 \\
\hline Stroke & $43(41)$ & $39(62)$ & $-9 \%$ & \\
\hline Seizure & $15(14)$ & $11(18)$ & $-36 \%$ & \\
\hline Headaches & $13(12)$ & $3(5)$ & $-77 \%$ & \\
\hline Non-organic & $8(8)$ & $0(0)$ & $-100 \%$ & \\
\hline Other & $25(24)$ & $10(16)$ & $-47 \%$ & \\
\hline Total neurological & 104 & 63 & $-41 \%$ & \\
\hline Cancer & 35 & 25 & $-28 \%$ & \\
\hline Care of elderly (falls, frailty) & 83 & 70 & $-16 \%$ & \\
\hline Digestive and hepatology & 75 & 57 & $-24 \%$ & 0.824 \\
\hline Miscellaneous & 77 & 42 & $-45 \%$ & \\
\hline Overdose and self-harm & 8 & 18 & $125 \%$ & 0.01 \\
\hline Total & 924 & 763 & $-17 \%$ & \\
\hline
\end{tabular}

The corresponding figures for the 2020 study period were 818 admissions, of whom, 55 resided outside the area. Findings are therefore based on 924 patients from 2017 (mean age 67 years), and 763 patients from 2020 (mean age 67.7 years), of whom, 235 had COVID-19. This represents a $43 \%$ fall in non-COVID-19 hospitalisations compared with 2017. A significantly greater proportion of those admitted in 2020 were male in comparison with 2017 (54\% vs 46\%; $p=0.02$ ). Final diagnoses are detailed in Table 2. Significant reductions in acute cardiac and respiratory emergencies (other than pneumonia and lung cancer) were noted, and there were fewer admissions with neurological illness and nonCOVID, non-pneumonic infections compared with 2017. The only traditional acute medical emergency to show a significant rise in 2020 was overdose and self-harm (chi-squared $=12.4 ; p<0.01$ ).

Among 235 admitted with COVID-19, comorbidities complicating their hospital stay included pneumonia and/or pneumonitis ( 174 patients; $74 \%$ ), acute kidney injury (64 patients;
$27 \%$ ), exacerbations of chronic obstructive pulmonary disease (COPD; 10 patients) heart failure (six patients), uncontrolled diabetes (six patients), stroke (three patients), pulmonary oedema (two patients), pulmonary embolus (two patients) and acute coronary syndrome (one patient).

Local causes of death are summarised in Table 3. There were 345 non-COVID deaths in 2020 compared with 311 deaths in 2017 (the $10.9 \%$ rise does reach significance; chi-squared $=$ 13.72; $p=0.02$ ). Over half of this rise was due to a composite of neurological disease including dementia and stroke. Deaths from cardiac causes rose by 18 (35\%); all the excess deaths compared with 2017 occurred in the 70-84 years age group. Deaths from cardiac disease are subdivided further in the table.

As no patients were admitted with non-valvular heart failure in the absence of acute coronary syndrome during the 2020 study period, deaths certified as being due to "chronic ischaemic heart disease' (ICD-10 code I25) and/or 'heart failure' (ICD-10 


\begin{tabular}{|c|c|c|}
\hline Disease classification & $\begin{array}{l}13 \text { March } \\
2017 \text { to } \\
9 \text { April } 2017 \text {, } \\
\text { n (\%) }\end{array}$ & $\begin{array}{l}23 \text { March } \\
2020 \text { to } \\
19 \text { April } \\
2020, \mathrm{n}(\%)\end{array}$ \\
\hline Cancer & $97(31)$ & $95(28)$ \\
\hline Circulatory & $54(16)$ & $72(21)$ \\
\hline Acute coronary syndrome/MI & 38 & 26 \\
\hline Cardiac failure or cardiomyopathy & 6 & 28 \\
\hline Atrial fibrillation & 1 & 6 \\
\hline Hypertensive heart disease & 1 & 8 \\
\hline Other cardiac or PE & 5 & 1 \\
\hline Aorta/arterial & 3 & 3 \\
\hline $\begin{array}{l}\text { Respiratory (including non-COVID } \\
\text { pneumonia) }\end{array}$ & $48(15)$ & $49(14)$ \\
\hline $\begin{array}{l}\text { Neurological (including dementia } \\
\text { and stroke) }\end{array}$ & $57(18)$ & $87(25)$ \\
\hline Digestive and liver & $12(4)$ & $18(5)$ \\
\hline Other & $43(14)$ & $24(7)$ \\
\hline COVID-19 & $n / a$ & 202 \\
\hline Total non-COVID deaths & $311(100)$ & $345(100)$ \\
\hline Total Deaths & 311 & $547^{a}$ \\
\hline
\end{tabular}

code I50) were re-examined. From these causes in 2020, there were 41 deaths (of whom two were aged less than 65 years), compared with 28 in 2017 (three aged under 65 years). Among those certified as dying from COVID-19 we found these factors may have contributed to 39 (19\%) of the COVID-19 deaths. We also examined comorbidities among the 18 patients aged less than 65 years and certified as having died from COVID-19. Among these, three had COPD, and one each had ischaemic heart disease and asthma.

Reductions in admissions with non-COVID infections and with exacerbations of cardiac and respiratory disease were especially prevalent among those aged less than 65 years (Table 4). Despite these reductions, non-COVID deaths occurred in only 46 people aged less than 65 years in 2020 compared with 49 in 2017. Lengths of stay in this age group were shorter in 2020 (mean 5.7 days; standard deviation (SD) 9.43; median 2 days; interquartile range (IQR) 4 days) compared with 2017 (mean 7.6 days; SD 16.2; median 3 days; IQR 7 days; $p<0.008$ ). Details by condition are shown in supplementary material $\mathrm{S} 1$. These results must be interpreted with caution because decisions on discharge timing may have been influenced by concerns about coronavirus within the hospital environment.

During the 2020 4-week study period, there were 3,974 deaths in Wales, of which 1,144 were recorded as being due to COVID-19 and 2,830 were due to other causes. During a corresponding 4-week block in 2019 there were 2,636 deaths. Therefore, the excess of Welsh deaths during the 2020 study period in which COVID-19 had not been implicated was only $1.07 \%$ in comparison with 2019.

Local atmospheric concentrations of $\mathrm{O}_{3}$ and $\mathrm{PM}_{2.5}$ did not differ during the two study periods, but much lower $\mathrm{NO}_{2}$ concentrations were found during 2020 (Fig 2). The differences were highly significant for roadside $\mathrm{NO}_{2}$ concentrations (Chepstow $21.2 \mathrm{\mu g} / \mathrm{m}^{3}$ vs $42.7 \mu \mathrm{g} / \mathrm{m}^{3}$; $p=0.000029$; and Hafod-yr-ynys $38.1 \mu \mathrm{g} / \mathrm{m}^{3}$ vs $65 \mu \mathrm{g} / \mathrm{m}^{3} ; \mathrm{p}=0.0000018$ ) and significant for background $\mathrm{NO}_{2}$ concentrations (Cwmbran $8.9 \mu \mathrm{g} / \mathrm{m}^{3}$ vs $12.9 \mu \mathrm{g} / \mathrm{m}^{3}$; $\mathrm{p}=0.03$; but not Newport $16.8 \mu \mathrm{g} / \mathrm{m}^{3}$ vs $18.7 \mu \mathrm{g} / \mathrm{m}^{3} ; \mathrm{p}=0.43$ ).

\section{Discussion}

During the first 4 weeks of national lockdown, our admissions with acute medical illness fell by $17.5 \%$, with non-COVID medical emergencies nearly halving, compared with a seasonally matched 4-week timeframe in 2017. Local deaths from non-COVID illness rose by only $10.9 \%$ during the pandemic compared with 2017 , and half of this increase was from neurological disorders including dementia and stroke.

\section{Strengths and limitations}

We examined contemporaneous admissions and deaths in a defined catchment area inhabited by a cross-section of urban and rural residents, including a diversity of ethnic backgrounds, and some of the most deprived areas in the UK. ${ }^{7}$ Also provided is local matched data on atmospheric concentrations of $\mathrm{NO}_{2}$, which are known to be higher than in other parts of Wales. ${ }^{7}$ The hospital's clinical portal is renowned for its comprehensive ascertainment potential, making it unlikely that admissions have been overlooked. The main limitation of this study is that among the 202 local patients and the 1,243 nationally who died of COVID-19, there would have been people with coexisting and life-threatening non-COVID illness. Special focus was therefore given to details of admissions and deaths from our local catchment area among those aged less than 65 years. In this age group there were only 18 COVID-19 deaths during the 2020 study period. According to ONS, a large majority of UK deaths occurring during the 4-week study period had proven, as opposed to suspected, COVID-19. ${ }^{8}$

Some illness reductions could be accounted for by patients in whom pre-existing comorbidity complicated and/or predisposed to COVID-19, and others with acute medical illnesses who harboured coronavirus without relevant symptoms. Analysis of active comorbidities occurring during hospitalisation among those with COVID-19 demonstrated that only pneumonia/pneumonitis and acute kidney injury occurred in more than $5 \%$ of these patients. Moreover, among the 202 people in whom COVID-19 was implicated as causing death, there were only 39 (19\%) with records of cardiac failure and/or chronic ischaemic heart disease among the contributory factors to death. We therefore consider that the observed plummeting of hospital presentations with cardiac disease and COPD, taken together with no rise in deaths from these causes in those aged less than 65 years, represents a genuine reduction in the incidence and/or severity of these emergencies.

Changes in referral routes may have accounted for part of the observed reductions in medical admissions. Given that there were 30 patients admitted electively or direct from outpatient clinics 
Table 4. All patients aged under 65 years admitted via the acute medical intake, together with all hospital and community deaths in this age group during two 4-week study periods

\begin{tabular}{|c|c|c|c|c|}
\hline & 2017 admissions & 2017 deaths & 2020 admissions & 2020 deaths \\
\hline Myocardial infarction & 24 & 7 & 8 & 4 \\
\hline Cardiac failure & 5 & 0 & 0 & 2 \\
\hline Other cardiac & 16 & 0 & 7 & 1 \\
\hline Total cardiac & $45^{a}$ & 7 & $15^{a}$ & 7 \\
\hline Asthma exacerbation & 10 & 0 & 6 & 0 \\
\hline COPD Exacerbations & 8 & 3 & 2 & 2 \\
\hline Non-COVID pneumonia & 31 & 2 & 31 & 2 \\
\hline COVID-19 & $\mathrm{n} / \mathrm{a}$ & $\mathrm{n} / \mathrm{a}$ & 88 & 18 \\
\hline Other infections & $81^{b}$ & 1 & $21^{b}$ & 2 \\
\hline Overdose/self-harm & 8 & 2 & 14 & 1 \\
\hline Other diseases including cancer & 164 & 34 & 101 & 32 \\
\hline \multirow[t]{2}{*}{ Total } & 347 & 49 & 278 & $64^{\mathrm{C}}$ \\
\hline & & & & (46 non-COVID-19) \\
\hline
\end{tabular}

${ }^{a}=p<0.01 ;{ }^{b}=p<0.001 ;^{c}=04$ June 2020, five deaths remain uncertified awaiting coroner inquests; COPD = chronic obstructive pulmonary disease.

during the 2017 timeframe, compared with 10 in 2020, the effect of this confounder on the overall numbers was small.

Another caveat is that acute medical illnesses may be occurring in the community just as frequently, with people less likely to seek medical help. Our data on local deaths demonstrates non-COVID mortality was little different from 2017, and indeed some of the rise in mortality from dementia, stroke and cardiac failure in those aged over 70 years could have included some people with undiagnosed COVID-19. The slightly lower death rate and shorter lengths of hospital stay among those aged less than 65 would also be consistent with reduced illness severity, though reluctance to remain in hospital during the pandemic may have prompted earlier discharges.

\section{Comparison with other studies}

Large reductions were seen among those hospitalised with benign (non-COVID and non-pneumonic) respiratory disease, mainly reflecting fewer exacerbations of asthma and COPD. Despite these reductions, deaths in this category were unchanged compared with 2017. These findings may be partly explained by reductions in atmospheric pollution. ${ }^{9}$ Reviews of aetiological

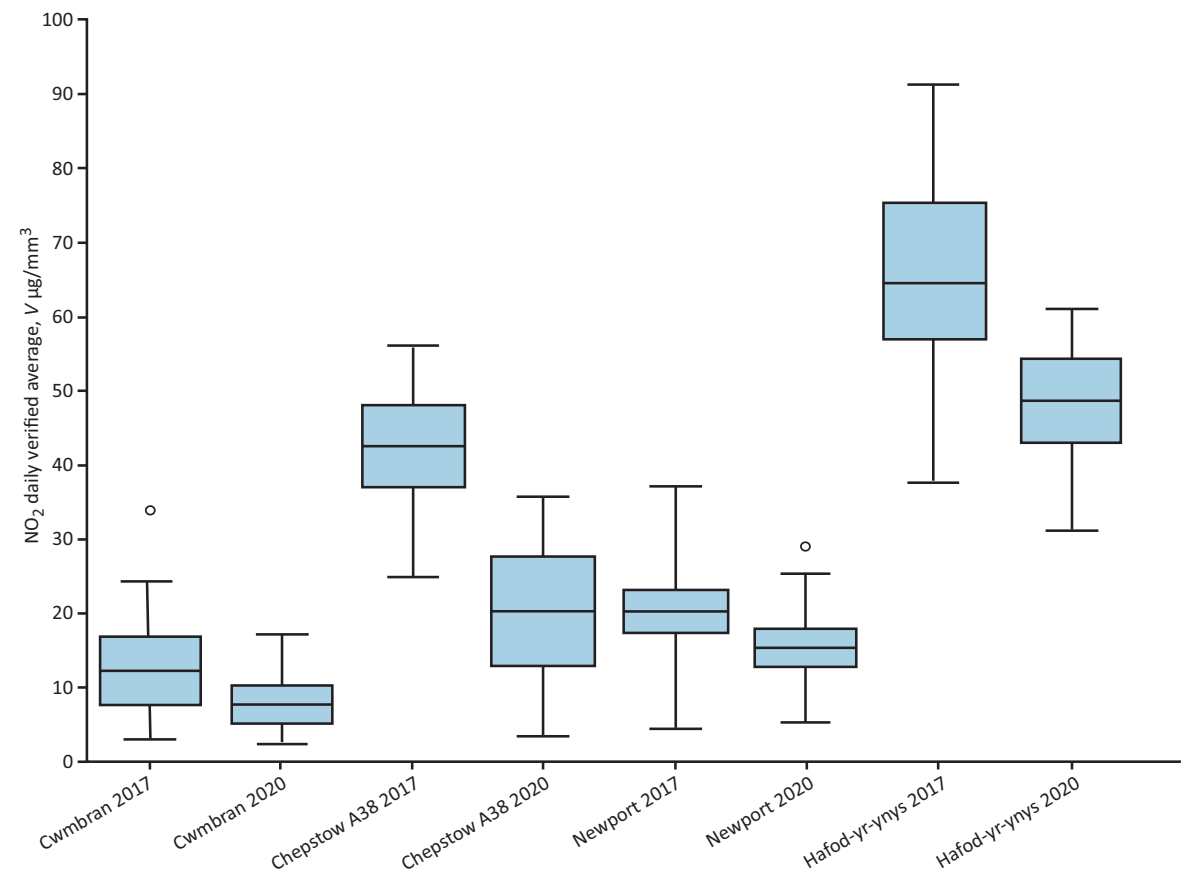

Fig 2. Atmospheric $\mathrm{NO}_{2}$ concentrations at two local roadside (Chepstow and Hafod-yr-ynys) and two background measurement stations (Cwmbran and Newport). 
factors in both COPD and asthma point to air pollution as a driver for exacerbations of these diseases. ${ }^{10,11}$ There is evidence that $\mathrm{NO}_{2}$ concentrations have a larger impact on admissions with respiratory illness than other atmospheric pollutants. ${ }^{12}$ There is local primary care data to support a disproportionate reduction in presentations with both influenza and exacerbations of severe asthma, and such consultations remain well below corresponding 2019 figures. $^{13}$

Poor air quality has been linked to acute myocardial infarction (MI) and exacerbations of heart failure. ${ }^{14,15}$ Alterations in $\mathrm{NO}_{2}$ concentrations are reported to influence hospitalisation rates for cardiovascular disease within a matter of days. ${ }^{16}$ Indeed, triangulation between air pollution and socio-economic deprivation might help to explain the link between deprivation and diagnosis of heart failure. ${ }^{17}$

Changes in working patterns during lockdown would be expected to reduce occupational exposure to dusts and chemicals and perhaps paused some of the adverse cardiovascular risks associated with both long working hours and shift working. ${ }^{18-21}$ There is also recent evidence that night shift working may provoke the development of short- and long-term adverse cardiovascular biomarkers. $^{22}$

Social distancing may have heralded the significant reductions in non-COVID and non-pneumonic infections in 2020 compared with 2017. Some infections may be associated with a pro-thrombotic tendency. ${ }^{23}$ A Danish study has linked infection with Streptococcus pneumoniae and influenza virus to MI, which confirms suggestions from earlier studies. ${ }^{24-27}$ There is even evidence to support benefit from influenza vaccination in reducing acute coronary events and cardiac failure and large-scale confirmatory studies are underway. ${ }^{28-33}$ Infections, in general, are well known to exacerbate asthma, COPD and diabetes.

Several changes in behaviour and lifestyle within Table 1 would be expected to reduce instances of acute psychological stress during lockdown. Acute stress can contribute to ill health via excessive and sustained sympathetic arousal aggravating ischaemic heart disease and other complications of hypertension. ${ }^{34-36}$ For example, MI occurs more commonly on Monday mornings among the working population and among Japanese women on a Saturday. ${ }^{37,38}$ Likewise, in the Swedeheart study, MI occurred more commonly at times when families congregate for Christmas and New Year, and on Easter Monday, but not on New Year's Eve or Easter Sunday. ${ }^{39}$ While that study did not demonstrate an association between spectator sport and MI, a large recent meta-analysis has shown rises in both fatal and non-fatal MI after watching football matches, and the effects were most marked among males (risk ratio (RR) 1.13 for fatal and 1.51 for non-fatal $\mathrm{MI}$ ), and among supporters of the losing team (RR 1.29) compared with those of the winning team (RR 0.80). ${ }^{40}$ Acute stress may also precipitate exacerbations of asthma, COPD and diabetic ketoacidosis. ${ }^{41-44}$ Our finding of fewer presentations with some of these conditions could also reflect more time being devoted to self-management and adherence to regular medication, and even perhaps aerobic exercise. ${ }^{5}$

Consultation and referral behaviour influence variations in patients presenting as neurological emergencies. While the incidence of stroke remained unchanged, presentations with epileptic seizures halved, possibly from lower stress and fewer external stimuli such as flashing lights and alcohol intoxication. ${ }^{45}$ Overnight admissions with acute headache fell considerably, and perceived non-organic (functional) neurological disorders did not occur during the 2020 period. In parallel, our emergency department observed an $86 \%$ reduction in inappropriate attendances (Richards AJ, personal communication).

While triggers of acute psychological stress have reduced, many people fear for their education, employment and the economy following the pandemic. The only traditional medical emergency category that rose in frequency on the medical take during 2020 was overdose and self-harm. The long-term psychiatric consequences of lockdown may eventually outweigh some of the medium-term physical health benefits we have observed.

It is informative to learn from the experience of Italy, in which the pandemic peaked 23 days before the UK. ${ }^{46}$ Unfortunately, in Lombardy, health services were overwhelmed, perhaps contributing to the rise in non-COVID mortality. ${ }^{4}$ More recent data from Italy (Istituto Nazionale di Statistica; ISTAT) indicates reductions in non-COVID deaths compared with the corresponding seasons in previous years. ${ }^{47}$ By contrast, the UK reported fewer deaths from ischaemic heart disease, cerebrovascular disease and lower respiratory disease in March 2020 versus a historic 5-year average for March. ${ }^{48}$ Appleby suggested that some of these deaths may have masqueraded as COVID-19. ${ }^{3}$ More recent data from a very large UK registry confirms a major reduction in admissions with acute coronary syndromes during March 2020 and April 2020. In that study, it was concluded that 'The reduced ... admissions ... is likely to have resulted in increases in out-of-hospital deaths and long-term complications of myocardial infarction and missed opportunities to offer secondary prevention treatment for patients with coronary heart disease. ${ }^{49}$ Although based on a much smaller sample, the data from our under 65 age group, in whom COVID-19 was uncommon, indicates that the reduction in presentations with many cardiac and respiratory emergencies indeed reflects a reduced incidence without a contemporaneous rise in deaths from these causes in the community.

The local $11 \%$ rise in non-COVID deaths compares with a rise of only $1 \%$ in Wales during the study period. This discrepancy may have been influenced by the earlier peak in deaths from COVID-19 in our catchment area (second week) compared with other areas in Wales (third week), with putative beneficial health effects due to changes in behaviour and lifestyle commencing before the first week of the study period in the other areas.

\section{Conclusion}

An ISTAT report in June noted 'reduction in the share of total excess mortality not covered by COVID-19 is a very important result of this report. With the data today available, only two possible causes can be hypothesized: the diagnostic capacity of healthcare facilities has increased and therefore the cases of COVID-19 have been diagnosed more accurately; indirect mortality not related to the virus but caused by the crisis of the hospital system in the most affected areas has decreased. The latter improves as pressure on health systems reduces. ${ }^{.50}$ Given that hospitals in Wales have not been overwhelmed during the pandemic, we believe our findings generate a third hypothesis, that changes in lifestyle and behaviour as a result of lockdown have brought about unforeseen reductions in the incidence and/or severity of some acute medical illnesses, in particular, exacerbations of cardiac and respiratory disease. If confirmed by others, it is to be hoped that the findings will act as a further stimulus to bear down on triggers of atmospheric pollution and non-COVID infection. 
Summary

What is known?

During the acceleration phase of the COVID-19 pandemic the numbers of patients presenting to emergency departments fell by half, and medical assessment units noted large reductions in non-COVID patients referred as medical emergencies. Hitherto, it has been assumed these reductions reflect altered referral behaviour and reluctance to seek medical help.

\section{What is the question?}

We hypothesised that changes in population behaviour and lifestyle might have led to genuine decreases in incidence and severity of some acute medical illnesses. Putative mechanisms include changes in work-life balance including more exercise, and reductions in both atmospheric pollution and non-COVID infection from social distancing.

\section{What we found?}

Despite striking reductions in admissions with cardiological, nonmalignant non-pneumonic respiratory illness and non-COVID non-pneumonic infection, local deaths from these causes proved only slightly higher than in 2017 and were actually lower among those aged less than 65 years. Deaths from causes other than COVID-19 in the whole of Wales were only $1 \%$ higher than in 2019.

\section{What are the implications for practice now?}

The results suggest that reductions in hospitalisations with some non-COVID acute medical illnesses may indeed reflect reduced incidence and severity of non-COVID infections and exacerbations of both cardiac and respiratory disease during lockdown. There is abundant literature to support our hypothesis that changes in population behaviour and lifestyle brought about unforeseen health benefits..

\section{Supplementary material}

Additional supplementary material may be found in the online version of this article at www.rcpjournals.org/clinmedicine: S1 - Length of stay among those aged less than 65 years admitted during two 4 -week blocks.

\section{Acknowledgements}

Rebecca Holley at the ONS undertook the deaths searches and the Newport Register Office kept us informed on numbers of local deaths. Newport coroner's officers advised on numbers of local cases awaiting inquests. The Aneurin Bevan University Health Board (ABUHB) Informatics Department, including Mr Robin Rice, lead for the clinical workstation portal, and his team, and Daniel Grenyer for assistance with death data analysis. Charlotte Bermingham, Greg Ceely and Jasper Morgan at ONS provided additional analysis on air quality and population characteristics. We acknowledge the support received from Dr Sarah Aitken, interim medical director, and Prof Sue Bale, R\&D lead, ABUHB. Alan Fraser, professor of cardiology at Cardiff University prereviewed the manuscript and made important suggestions. We thank the referees of the paper for prompting us to seek local information on air pollution to complement our findings. Finally, we wish to pay tribute to the consultant physicians and intensivists and their junior staff and all nursing staff who bore the brunt of managing these patients under such challenging circumstances. Many colleagues have given advice and made suggestions during the data gathering and presentation at the Postgraduate Centre, Royal Gwent Hospital.

\section{References}

1 West D. Some hospitals left 'quiet' as covid-19 sparks huge fall in attendances. HSJ, 2020. www.hsj.co.uk/acute-care/some-hospitals-leftquiet-as-covid-19-sparks-huge-fall-in-attendances/7027244.article

2 Thornton J. A\&E visits fall by $25 \%$ after lockdown. BM] 2020;369:m1401.

3 Appleby J. What is happening to non-covid deaths? BMJ 2020;369:m1607.

4 Piccinini M, Rohmann JL, Foresti L, Lurani C, Kurth T. Use of all cause mortality to quantify the consequences of covid-19 in Nembro, Lombardy: descriptive study. BMJ 2020;369:m1835.

5 Office for National Statistics. Coronavirus and how people spent their time under lockdown: 28 March to 26 April 2020.ONS, 2020. www.ons.gov.uk/economy/nationalaccounts/satelliteaccounts/ bulletins/coronavirusandhowpeoplespenttheirtimeunderrestrictions /28marchto26april2020

6 Office for National Statistics. Analysis of death registrations not involving coronavirus (COVID-19), England and Wales: 28 December 2019 to 1 May 2020. ONS, 2020. www.ons.gov.uk/ peoplepopulationandcommunity/birthsdeathsandmarriages/ deaths/articles/analysisofdeathregistrationsnotinvolvingcorona viruscovid19englandandwales28december2019to1may2020/ technicalannex\#deaths-due-to-dementia-and-alzheimer-disease

7 Welsh Government. Welsh index of multiple deprivation (WIMD) 2019: Results report. Welsh Government, 2019.

8 Office for National Statistics. Deaths involving COVID-19, UK: deaths occurring between 1 March and 30 April 2020. ONS, 2020. www.ons.gov.uk/peoplepopulationandcommunity/birthsdeathsandmarriages/deaths/bulletins/deathsinvolvingcovid19uk/death soccurringbetween 1 marchand30april2020

9 The Earth Observatory. Airborne nitrogen dioxide plummets over China. NASA, 2020. www.earthobservatory.nasa.gov/ images/146362/airborne-nitrogen-dioxide-plummets-overchina

10 Salvi SS, Barnes PJ. Chronic obstructive pulmonary disease in nonsmokers. Lancet 2009;374:733-43.

11 Guarnieri M, Balmes JR. Outdoor pollution and asthma. Lancet 2014;383:1581-92.

12 Pannullo F, Lee D, Neal L et al. Quantifying the impact of current and future concentrations of air pollutants on respiratory disease risk in England. Environ Health 2017;16:29.

13 Public Health Wales. Rapid COVID-19 surveillance. NHS Wales, 2020. https://public.tableau.com/profile/public.health.wales. health.protection\#!/vizhome/RapidCOVID-19virology-Public/ Headlinesummary [Accessed 21 October 2020].

14 Buszman PE, Derbisz K, Kwasiborski P et al. Impact of air pollution on hospital patients admitted with ST- and non-ST-segment elevation myocardial infarction in heavily polluted cities within the European Union. Cardiol ] 2020;27:541-7.

15 Shah AS, Langrish JP, Mills NL. Global association of air pollution and heart failure: a systemic review and meta-analysis. Lancet 2013:382:1039-48.

16 Collart P, Dubourg D, Leveque A, Bustos Sierra N, Coppieters Y. Short-term effects of nitrogen dioxide on hospital admissions for cardiovascular disease in Wallonia, Belgium. Int J Cardiol 2018;255:231-6.

17 Ujil A, Koundstaal S, Direk K et al. Risk factors for incident heart failure in age- and sex-specific strata: a population-based cohort using linked electronic health records. Eur ] Heart Failure 2019;21:1197-206.

18 Lemiere C, Begin D, Camus M et al. Occupational risk factors associated with work-exacerbated asthma in Quebec. Occ Health Envir Med 2012;69:901-7.

19 Tarlo SM, Malo J-L, de Blay F et al. An official American Thoracic Society Workshop Report: Presentations and discussion of the sixth Jack Pepys workshop on asthma in the workplace. Ann Am Thorac Soc 2017;14:1361-72. 
20 Kivimaki M, Jokela M, Nyberg ST et al. Long working hours and risk of coronary heart disease and stroke: a systemic review and meta-analysis of published and unpublished data for 603,838 individuals. Lancet 2015;386:1739-46.

21 Torquati L, Mielke GI, Brown W], Kolbe-Alexander T. Shift work and the risk of cardiovascular disease. A systematic review ana metaanalysis including dose-response relationship. Scand J Work Environ Health 2018:44:229-38.

22 Johnson CY, Tanz LJ, Lawson CC et al. Night shift work and cardiovascular disease biomarkers in female nurses. Am J Ind Med 2020;63:240-8.

23 Butchart $\mathrm{EG}$, Ionescu $\mathrm{A}$, Payne $\mathrm{N}$ et al. A new scoring system to determine thromboembolic risk after heart valve replacement. Circulation 2003;108 (suppl II):II68-74.

24 Ohland J, Warren-Gash C, Blackburn R et al. Acute myocardial infarctions and stroke triggered by laboratory-confirmed respiratory infections in Denmark, 2010-2016. Euro Surveill 2020;25:p111900199.

25 Warren-Gash C, Smeeth L, Hayward AC. Influenza as a trigger for acute myocardial infarction or death from cardiovascular disease: a systematic review. Lancet Infect Dis 2009;9:601-10.

26 Barnes M, Heywood AE, Mahimbo A et al. Acute myocardial infarction and influenza: a meta-analysis of case-control studies. Heart 2015;101:1738-47.

27 Kwong JC, Schwartz KL, Campitelli MA et al. Acute myocardial infarction after laboratory-confirmed influenza infection. $N$ Engl ] Med 2018:378:345-53.

28 Abinader EG. Influenza vaccination and reduced risk of myocardial infarction. Isr Med Assoc J 2003;5:839.

29 Johnstone J, Loeb M, Gao P et al. Influenza vaccination and major adverse vascular events in high-risk patients. Circulation 2012;126:278-86.

30 Vardeny $\mathrm{O}$, Claggett B, Udell JA et al. Influenza vaccination in patients with chronic heart failure: The PARADIGM-HF trial. JACC Heart Fail 2016;4:152-8.

31 Mesquita ET. Infections in heart failure - impact on mortality. Arq Bras Cardiol 2018:110;371-2.

32 Frobert O, Gotburg M, Angeras $\mathrm{O}$ et al. Design and rationale for the influenza vaccination after myocardial infarction trial. Am Heart ] 2017:189:94-102.

33 Loeb M, Dokainish H, Dans A. Randomized controlled trial of influenza vaccine in patients with heart failure to reduce adverse vascular events: rationale and design. Am Heart J 2019;212:36-44.

34 Steptoe A, Kivimaki M. Stress and cardiovascular disease. Nat Rev Cardiol 2012;9:360-70.

35 Leeka J, Schwartz BG, Kloner RA. Sporting events affect spectators' cardiovascular mortality: it is not just a game. Am J Med 2010;123:972-7.

36 Liu M-Y, Li N, Li WA, Khan H. Association between psychological stress and hypretension: a systematic review and meta-analysis. Neurol Res 2017;39:573-80.
37 Willich SN, Lowel H, Lewis M et al. Weekly variation of acute myocardial infarction. Increased Monday risk in the working population. Circulation 1994;90:87-93.

38 Kinjo K, Sato H, Sato H et al. Variation during the week in the incidence of acute myocardial infarction: increase for Japanese women on Saturdays. Heart 2003;89:398-403.

39 Mohammad MA, Karlsson S, Haddad ] et al. Christmas, national holidays, sports events and time factors as triggers of acute myocardial infarction: SWEDEHEART observational study 1998-2013. BMJ 2018;363:k4811.

40 Lin L-L, Gu H-Y, Yao Y-Y et al. The association between watching football matches and the risk of cardiovascular events: A metaanalysis. J Sports Sci 2019;37:2826-34.

41 Barnthouse M, Jones BL. The impact of environmental chronic and toxic stress on asthma. Clin Rev Allergy Immunol 2019;57:427-38.

42 Yohannes AM, Dryden S, Hanania NA. Validity and responsiveness of the depression anxiety stress scales - 21 (DASS-21) in COPD. Chest 2019;155:1166-77.

43 Butler AM, Weller BE, JP Yi-Frazier et al. Diabetes-specific outcomes and general live stress and glycaemic outcomes in emerging adults with Type 1 diabetes: Is race/ethnicity a moderator? J Paed Psych 2017:92:930-40.

44 Umpierrez G, Kitabchi AE. Diabetic ketoacidosis: risk factors and management strategies. Treat Endocrinol 2003;2:95-108.

45 Galtrey CM, Mula M, Cock HR. Stress and epilepsy: fact or fiction, and what can we do about it? Pract Neurol 2016;16:270-8.

46 World Health Organization. WHO coronavirus disease (COVID-19) dashboard. WHO, 2020. https://covid19.who.int [Accessed 05 ]une 2020].

47 Istituto di Nazionale Statistica. Mortality of the resident population. Istat, 2020. www.istat.it/en/archivio/242152

48 Office for National Statistics. Deaths involving COVID-19, England and Wales: deaths occurring in March 2020. ONS, 2020. www. ons.gov.uk/peoplepopulationandcommunity/birthsdeathsandmarr iages/deaths/bulletins/deathsinvolvingcovid19englandandwales/ deathsoccurringinmarch2020

49 Mafham MM, Spata E, Goldacre R et al. COVID-19 pandemic and admission rates for and management of acute coronary syndromes in England. Lancet 2020;396:381-9.

50 Istituto di Nazionale Statistica. Report on impact of the COVID-19 epidemic on the total mortality. Istat, 2020. www.istat.it/en/ archivio/243805

Address for correspondence: Dr Miles C Allison, Division of Unscheduled Care, Department of Gastroenterology and Hepatology, 'A' Block, Royal Gwent Hospital, Cardiff Road, Newport NP20 2UB, UK.

Email: miles.allison@wales.nhs.uk Twitter: @a1_miles 